\title{
Tachycardia: The hidden cardiovascular risk factor in uncomplicated arterial hypertension
}

\author{
Katarzyna Cierpka-Kmieć, Dagmara Hering
}

Department of Hypertension and Diabetology, Medical University of Gdansk, Poland

\begin{abstract}
Early detection and management of elevated blood pressure is crucial in reducing the burden of cardiovascular disease (CVD). The importance of an absolute risk assessment and patient risk stratification has been highlighted in the European hypertension guidelines since 2003. Amongst numerous risk factors influencing patient prognosis, elevated heart rate (HR) has been indicated as important predictor of future risk of hypertension, coronary heart disease, sudden cardiac death, heart failure, CVD, stroke, total cancer and mortality. Given that resting $H R$ can be easily determined in clinical practice and modified by lifestyle changes as well as beta-blocker therapy, it seems reasonable that lowering resting $H R$ should be a potential target to reduce disease burden and premature mortality. However, there is a lack of outcome studies of HR lowering in tachycardia-related hypertension. This review outlines the underlying mechanisms of early course hypertension pathophysiology with the critical role of the sympathetic nervous system activation, the prognostic significance of fast HR and the mechanistic rationale for the use of non-pharmacological approaches and/or highly long-acting cardioselective beta-blockers with some consideration given to betaxolol properties. (Cardiol J 2020; 27, 6: 857-867)
\end{abstract}

Key words: essential hypertension, tachycardia, cardiac output, peripheral resistance, muscle sympathetic nerve activity, non-pharmacological approaches, betaxolol

\section{Introduction}

Hypertension remains the leading preventable cause of premature deaths worldwide. Despite advances in hypertension prevention, diagnosis and treatment, elevated blood pressure (BP) affects at least one third of the adult global population according to national surveys $[1,2]$. Using the recent American College of Cardiology and the American Heart Association guidelines for hypertension definition, the overall burden of the disease is even higher [3], likely to rise further due to the increasing prevalence of obesity worldwide. Notably, the incidence of cardiovascular (CV) disease (CVD) (i.e. myocardial infarction [MI], stroke, heart failure $[\mathrm{HF}]$, peripheral artery disease, kidney disease) directly increases from the threshold of
115/75 mmHg in all age groups, in both men and women [4].

Essential hypertension is the most common form of hypertension with no identifiable cause affecting nearly $95 \%$ of hypertensive patients. The pathogenesis of primary hypertension is multifactorial and numerous interrelated factors including salt intake, obesity, insulin resistance, genetics, endothelial dysfunction, low birth weight, intrauterine malnutrition and vascular anomalies contribute to raised $\mathrm{BP}$ and its relative impact may vary between individuals.

Further emerging risk factor gaining an important recognition is elevated resting heart rate (HR). Tachycardia can reflect a normal body response to various stimuli such as stress, fever, alcohol, smoking, coffee, strenuous exercise or associated

Address for correspondence: Prof. Dagmara Hering, MD, PhD, Department of Hypertension and Diabetology,

Medical University of Gdansk, ul. Dębinki 7c, 80-952 Gdańsk, Poland, tel: +48 58349 2065, fax: +48 583492601 ,

e-mail: hering@gumed.edu.pl

Received: 11.01.2019 Accepted: 4.02.2019 
conditions (e.g. anemia, thyroid problems, infection, other). While in clinical practice fast HR can be unnoticed or viewed as a sign of 'nervousness', there is evidence to indicate that the presence of tachycardia and increased cardiac output (CO) are hemodynamic features of early phase of arterial hypertension [5] and important contributors to established hypertension and CVD [6]. Most studies on hypertension have reported that a HR higher than 80-85 bpm confers increased CV and mortality risk [6]. Although the presence of HR of $>80 \mathrm{bpm}$ has been added to patient risk evaluation as per recent European Society of Cardiology and the European Society of Hypertension guidelines [7], the use of beta-blockers in uncomplicated hypertension is still under debate and the therapeutic approach to patients presenting with hypertension-related tachycardia remains empirical. CV outcomes of hypertensive patients treated or non-treated with beta-blockers are inconclusive. Optimal HR levels for hypertensive patients need to be determined.

\section{Hemodynamic pattern of essential hypertension}

Hemodynamic characteristics of the initial phase of primary essential hypertension are not unequivocal, either induced by raised $\mathrm{CO}$ or increased peripheral resistance [8]. It has been documented that in not less than $30 \%$ of children and younger population, fast $\mathrm{HR}$ and $\mathrm{CO}$ but normal total peripheral resistance precedes the development of high BP. The Tecumseh Blood Pressure Study found that $37 \%$ of all patients with untreated borderline and/or mild hypertension demonstrated hyperkinetic state with elevated $\mathrm{HR}, \mathrm{CO}$, forearm blood flow and plasma noradrenaline (NA) levels resulting in high sympathetic tone and decreased parasympathetic tone [9]. The hyperkinetic state caused by excessive autonomic drive is likely to be induced by augmented sympathetic activity to the heart and kidney. This selectively elevated NA release from renal and cardiac sympathetic nerves in essential hypertension has been predominantly found in males under the age of 40 [10].

High sympathetic activity is likely to be the underlying mechanism through which HR is associated with high insulin levels, insulin resistance, dyslipidemia, high hematocrit and excess body weight. Indeed, patients with hypertension commonly display other metabolic abnormalities including elevated glucose, insulin and lipid levels which importantly contribute to the HR increase $[11,12]$. Weight gain and a lack of physical activity are further independent factors associated with resting tachycardia. Accelerated HR is associated with the magnitude of BP levels [13-16]. Own clinical experience suggests that pre-diabetes and obstructive sleep apnea are not uncommon conditions associated with tachycardia-related hypertension (as summarized in Fig. 1).

With aging and disease progression, $\mathrm{CO}$ generally normalized in uncomplicated hypertension, however a shift toward increased vascular resistance potentiates sympathetic activation which is a hallmark of established hypertension. In uncontrolled hypertension, persistent sympathetic activation promotes vascular remodeling, organ damage and adverse CV complications (Fig. 1) [17].

Fast HR in turn not only increases BP and leads to sustained hypertension but also exerts hemodynamically mediated cardiac abnormalities leading to reduced coronary flow reserve and vascular compliance, promoting atherosclerosis, arterial remodeling and plaque instability, endothelium dysfunction and microalbuminuria, importantly contributing to myocardial ischemia, coronary artery disease and HF (Fig. 1). Subsequently, the risk of ischemic heart disease, MI, cardiac arrhythmia and sudden cardiac death have been closely linked to the increased magnitude of HR [18].

\section{Sympathetic activation in essential hypertension}

Neurogenic activation underlies no less than $50 \%$ of all cases of high BP [19]. With the use of two state of the art methods such as the isotope dilution technique (to estimate the release of NA from the sympathetic nerves innervating internal organ) and the technique of microneurography (to directly assess postganglionic muscle sympathetic nerve activity [MSNA]), it has been documented that hypertension is commonly neurogenic, with the rise in BP being initiated and sustained as a result of potentiated sympathetic activation in the kidney and the heart - the two organs critically involved in neural control of circulation and BP [19, 20]. Increased activity of MSNA has been found in low risk subjects with high-normal BP [21] suggesting that neurogenic excitation may precede overt arterial hypertension [22]. A long-term study documented that in subjects with prehypertension MSNA tracking corresponds with BP changes over time suggesting that tonic activation is likely to influence a time-related increase in resting BP and development of sustained hypertension in prehypertension [23]. In patients with resistant 


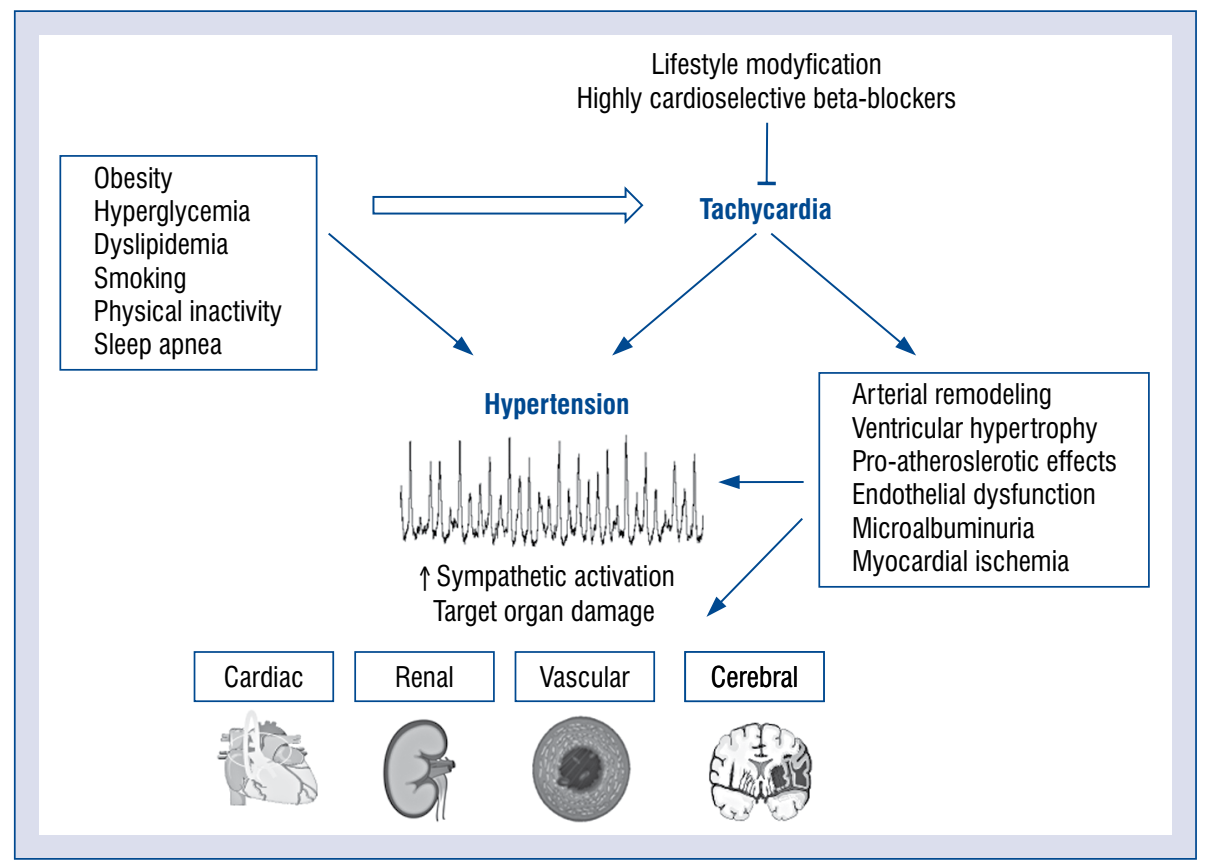

Figure 1. Factors contributing to elevated heart rate and pathophysiological consequences of tachycardia.

hypertension, sympathetic activation is further potentiated, reaching the MSNA levels directly corresponding to HR levels [24, 25]. Furthermore, sympathetic nervous system activation has been documented as the underlying critical cause of hypertension-mediated organ damage [26-28] and independent predictor of mortality and poor CV outcomes [29].

\section{Link between tachycardia and sympathetic activation}

Tachycardia and resultant hyperkinetic circulation if sustained over time, leads to an autonomic imbalance and reduced heart rate variability [30]. Microneurographic studies found that sympathetic activity and HR exerts an interactive effect on BP levels [31]. In normotensive subjects (males only, not females) with faster HR, higher levels of MSNA has been linked to higher systolic BP and pulse pressure whereas no similar relationship could be found in subjects with lower HR [31]. On the contrary, the relationship between resting HR and MSNA in hypertension is more complex and not completely understood. It has been documented that HR may be not a reliable indicator of the overall sympathetic activity as no association has been found between supine resting office HR and MSNA in essential hypertension [32]. Notably, ambulatory $\mathrm{HR}$ was found to be a superior risk marker to clinic or HR derived from an electrocardiogram (ECG) [33]. Indeed, when 24-h ambulatory BP measurements were applied, MSNA levels have been directly related to ambulatory daytime and night-time HR in a large sample of patients with untreated essential hypertension that were independent of age, body mass index (BMI) and gender [34]. This observation is likely to explain recent findings demonstrating the predictive role of masked (and/ /or sustained) tachycardia but not office tachycardia in future CV events and mortality [35].

\section{Heart rate as risk factor for cardiovascular disease}

Over the past decade elevated HR has gained recognition as an important risk factor for the development of CVD. Numerous epidemiological studies have reported an independent association between tachycardia and CV morbidity and mortality in the general population [18], subjects with prehypertension, patients with hypertension [12], CVD [36], HF [37], total cancer and all-cause mortality [38]. The prognostic value of both home [39] and ambulatory HR [40] has been indicated in the Ohasama Study which included individuals from the Japanese general population with no previous history of CVD including arrhythmia. An increase of $5 \mathrm{bpm}$ in the morning home HR measurement was associated with a $17 \%$ increase in risk of $\mathrm{CV}$ 
mortality which remained statistically significant after adjustment for home BP values. Moreover, even subjects with $\mathrm{HR} \geq 70 \mathrm{bpm}$ and homemeasured systolic BP within the normal range $(<135 \mathrm{mmHg}$ ) had a higher risk of CV mortality compared to those with normal systolic BP and HR values [39]. Further analysis of the Ohasama study revealed that both daytime and nighttime HR predicted all-cause mortality over a 12 -year period, however only nighttime HR remains the most important and independent predictor of nonCV mortality [40].

Further proof for the predictive role of $\mathrm{HR}$ on $\mathrm{CV}$ morbidity primarily in hypertensive men comes from the Framingham study suggesting that HR and BP may act synergistically in the development of CV complications [13]. Supportive evidence for fast HR-related outcomes was also documented in the Valsartan Antihypertensive Long-Term Use Evaluation (VALUE) trial which included patients with high-risk hypertension followed over a 5-year period [41]. It was found that patients in the highest HR quintile had a greater risk for cardiac events when compared to patients in the lowest HR quintile [41]. Notably, the adverse impact of elevated HR on patient prognosis was unrelated to BP control indicating that even patients with reasonably well-controlled hypertension but the presence of tachycardia are at high risk for CV events.

Tachycardia is also a strong predictor of excessive coronary morbidity and CV mortality [42]. A large study of French population found that accelerated resting $\mathrm{HR}$ was an independent predictor of non-CV mortality in both genders, and CV mortality in men, independent of age and the presence of hypertension [14]. In this study the HR-related increase in CVD mortality was due to a rise in coronary death but not cerebrovascular mortality. Another long-term study found that individuals with coexisting hypertension and elevated HR had increased risk of both stroke and coronary heart disease [43]. This is likely to occur as a result of plaque disruption due to hemodynamic forces (i.e. hypertension-induced left ventricular hypertrophy and elevated HR) which is a crucial pathophysiological mechanism underlying acute coronary syndrome and the progression of atherosclerosis [44].

There is evidence to indicate that not only masked hypertension is associated with an increased risk for CVD, but also masked tachycardia significantly increased rates of $\mathrm{CV}$ events and all-cause mortality [45]. Masked tachycardia has been defined as HR levels values $\leq 85 \mathrm{bpm}$ in the clinic, but an elevated HR out of the clinic (ambulatory mean nighttime $>76 \mathrm{bpm}$ ) [45]. Masked tachycardia may occur in as many as $10 \%$ of the hypertensive population, and is important because it is not diagnosed by routine medical examinations, but carries an adverse prognosis, both in terms of increased target organ damage and CV events. Possible characteristics of individuals with masked tachycardia are relatively young patients, smokers, sufferers of diabetes or other metabolic disorders, and those who have elevated HR in outpatient settings [45, 46]. The negative association between masked tachycardia and an increased risk for major $\mathrm{CV}$ events and all-cause mortality was documented in a study of 7602 patients with newly diagnosed hypertension who were followed over a duration of 5 years [45]. Patients presenting with sustained tachycardia (increased both HR in the office and ambulatory nighttime measurements) had an increased risk of major $\mathrm{CV}$ events, but not mortality. After adjustment for additional risk factors including age, gender, BMI, lipid profile and creatinine levels, but not smoking and diabetes, both masked and sustained tachycardia were associated with greater risk of $\mathrm{CV}$ events [45]. While the type of beta-blockers used has not been indicated in this study, it is notable that the prognostic significance of tachycardia in predicting future major adverse $\mathrm{CV}$ events is independent of beta-blocker use [45].

The prognostic significance of elevated resting HR has been also found in patients with resistant hypertension [33] in whom not only fast ( $>75 \mathrm{bpm}$ or $>70 \mathrm{bpm}$ for nighttime HR), but also slow HR ( $<60 \mathrm{bpm}$ or $<55 \mathrm{bpm}$ for nighttime HR) predicted CV death. Importantly, approximately $80 \%$ of patients from this cohort were treated with beta-blockers which had an impact on HR-related prognosis. Fast HR was a significant risk marker in patients using beta blockers, whereas slow HR was a predictor in those not using beta-blockers suggesting an overall U-shaped phenomenon between the levels of HR and outcomes in patients with resistant hypertension [33]. In view of these findings, it appears that despite achieved BP control, hypertensive patients can remain at high risk for $\mathrm{CV}$ and/or non-CV complications.

\section{Beta-blockers in hypertension}

Despite the mechanistic rationale for the use of beta-blockers in the treatment of hypertensionrelated tachycardia, their therapeutic usefulness has been questioned based on the outcomes from meta-analyses of clinical trials. It has been sug- 
gested that therapy with beta-blockers may not preclude future CV events and mortality in hypertension. Meta-analysis of a large cohort of patients $(\mathrm{n}=94,492)$ with hypertension found that therapy with beta-blockers led to an increased risk for newonset diabetes mellitus, occurrence of stroke with no benefit for the hard end-point of death or MI compared to other antihypertensive agents [47]. Further analysis of randomized controlled trials evaluating beta-blockers use in patients with hypertension $(n=34,096)$ when compared to patients $(\mathrm{n}=30,139)$ taking other antihypertensive agents or patients receiving placebo $(\mathrm{n}=3987)$ indicated that a lower HR (as attained in the beta-blocker group at study end) was associated with greater risk for end points of all-cause mortality, CV mortality, MI, stroke and HF [48]. Notably, nearly 75\% of all clinical studies used as reference, atenolol drug in randomized controlled trials of primary hypertension [49], whereas beta-blockers differ in their pharmacokinetic and pharmacodynamic properties which influence their therapeutic impact on patient profiles, and has been discussed elsewhere. The main CV use of beta-blockers is to antagonize cardiac beta1-adrenoceptor responses in the heart and kidneys, whereas some beta-blocking agents possess an affinity for specific beta2, alpha1 or beta3 receptors. The efficacy of beta-blockers depends on their mechanisms of action including the degree of their lipophilicity, hydrophilicity, drug metabolism related to gene polymorphism, intrinsic agonist activity, penetration through the blood-brain barrier, bioavailability, plasma half-life and vasodilation. Smoking status and alterations in central BP have also contributed to the negative impact of beta-blockers on outcomes in managing hypertension. Another meta-analysis reported no major differences in BP lowering between atenolol and other antihypertensive drug class, however, there was a significantly higher mortality, CV mortality and risk of stroke with atenolol treatment than with other active treatments [50, 51]. Further meta-analysis demonstrated the benefits of beta-blocker use in reducing CV endpoints in younger hypertensive subjects, but not in older patients suggesting that age or non-atenolol beta-blocker might be an important determinant of outcomes in response to beta-blockers in hypertension [52]. Most meta-analyses compared the effectiveness of beta-blockers on patient prognosis in hypertension with the use of atenolol, metoprolol, propranolol, and oxprenolol. Despite these findings, clinical trials comparing head-to-head outcomes between various beta-blockers (including beta-blockers with vasodilating effects) in the treatment of hypertension are lacking. Moreover, previous studies on beta-blockers have been primarily designed to treat elevated BP, but not to focus on hypertensionrelated tachycardia outcomes.

The use of cardio selective beta-blockers is associated with a lower risk of side effects including metabolic disorders [53], while binding beta2 receptors located in lungs, liver, vascular smooth muscle or skeletal muscle result in bronchospasm, peripheral vasoconstriction, alteration of glucose and lipid metabolism [54, 55]. Therapy with a cardioselective nebivolol (causing NO-derived vasodilation) and non-cardioselective carvedilol (causing inhibition of sympathetic alpha-receptors) is associated with less side effects and favorable metabolic profile in addition to pleiotropic action, anti-inflammatory, anticoagulation and antiproliferation properties. Nebivolol also positively affects adipose tissue via acting as an agonist for beta3 adrenoreceptors. Nevertheless, given the different mechanisms of action, the magnitude of HR reduction with either nebivolol or carvedilol will not only take longer in duration but is lower compared to cardio-selective beta-blockers without intrinsic sympathomimetic activity (i.e. atenolol, metoprolol, bisoprolol or betaxolol). Furthermore, increasing doses of metoprolol or bisoprolol caused further decreases in HR (as expected with beta-blockers), whereas increasing doses of carvedilol produced increases in HR, likely as the result of a reflex increase in sympathetic activity secondary to peripheral vasodilation caused by alpha-blocking effects of the drug. In fact, $200 \mathrm{mg}$ of metoprolol and $10 \mathrm{mg}$ of bisoprolol are significantly more effective in reducing HR than $100 \mathrm{mg}$ of carvedilol $[56,57]$. However, both metoprolol and bisoprolol have been shown to induce up-regulation of betaadrenoceptor density and to decrease nocturnal melatonin release [58-60].

Amongst beta-blockers, betaxolol is a long acting highly selective beta1-blocking agent (half-life $\sim 19 \mathrm{~h}$ ) and has several advantages that are likely to overcome certain limitations of other beta-blockers [61]. Betaxolol provides steady plasma concentration, less fluctuation and intersubject, and intrasubject variability producing a more consistent therapeutic response and more dependable dosage adjustment when compared to atenolol [62]. A further major advantage of betaxolol is the penetration through the blood-brain barrier and the ability to antagonize beta1 receptor that are expressed in several regions and tracts in the central nervous system [61] including the locus coeruleus (LC) 
and its projections. Notably, the LC is the major noradrenergic brain nuclei and the largest source of NA production. In this context, it is likely that betaxolol may influence the central nervous system. In fact, betaxolol administration resulted in a rapid reduction of panic anxiety and panic disorder attacks, even in patients with longstanding anxiety, obsessive-compulsive personality disorder and post-traumatic stress [61].

\section{Effects of beta-blockers on sympathetic activation in hypertension}

The contribution of increased sympathetic activation to the pathophysiology of hypertension is well established. The question therefore arises, how lowering the HR and BP will affect MSNA levels. Previous studies determining the effects of beta-blockers on sympathetic activity in essential hypertension have shown conflicting results. Atenolol therapy had no effects on plasma NA levels or total body NA spillover in essential hypertension [63]. Microneurography studies have also demonstrated inconsistent results with an increase in MSNA following a short-term therapy with metoprolol in patients with untreated essential hypertension [64] or increase in MSNA after acute administration of atenolol in healthy subjects [65]. Other studies reported no changes in MSNA in response to chronic therapy with metoprolol [66] and atenolol [67].

On the contrary, a recent study found age-related differences in hemodynamic and sympathetic profile in hypertension-related tachycardia and agedependent autonomic neural responses to betaxolol therapy [68]. An 8-week therapy with betaxolol resulted in HR and systolic BP decreases in all males with untreated essential hypertension and ambulatory tachycardia. However, the magnitude of HR reduction was greater in younger $(-29 \pm 4 \mathrm{bpm}$, $\mathrm{p}<0.001)$ than older subjects $(-17 \pm 4 \mathrm{bpm}$, $\mathrm{p}=0.002)$, whereas the degree of $\mathrm{BP}$ reduction was greater in older subjects $(-27 \pm 7 \mathrm{mmHg}$, $\mathrm{p}=0.007)$ compared to younger $(-13 \pm 4 \mathrm{mmHg}$, $\mathrm{p}=0.01$ ) males. In older subjects, despite BP and HR decreases, there was a significant decrease in MSNA $(-13 \pm 5$ bursts/min, $\mathrm{p}<0.05)$. No significant changes in MSNA ( $3 \pm 3$ bursts $/ \mathrm{min}, \mathrm{p}=0.47$ ) were found in younger males at 8 week followup. These findings suggest that betaxolol exerts favorable effects on autonomic neural control in hypertension-induced tachycardia irrespective of age. In this context, further longer-term clinical trials on betaxolol are required to determine $\mathrm{CV}$ outcomes in hypertension-related tachycardia.
Aside from effective HR, BP and MSNA control in hypertension-related tachycardia, therapy with betaxolol has been found favorable in reducing maternal BP without any deleterious effect on the fetus and the newborn [69]. Furthermore, recently a large case-control study in Taiwan found that patients with chronic obstructive pulmonary disease (COPD) taking selective beta-blockers had a lower risk of severe exacerbations compared to patients with COPD who experienced a higher risk of severe exacerbations during an increased mean daily dose of non-cardioselective beta-blockers [70]. Amongst selective beta-blockers which COPD patients were taking (i.e. acebutolol, atenolol, bisoprolol, betaxolol, metoprolol), in particular one selective beta-blocker betaxolol had a significantly lower risk of severe exacerbations. This study indicates that betaxolol may be the preferred choice of selective beta-blocker for patients with COPD, whereas non-cardioselective beta-blockers should not be prescribed for patients with COPD.

\section{Non-pharmacological treatment of tachycardia}

Considering the contribution of elevated HR to the development of arterial hypertension and patient prognosis, interventions aiming at lifestyle changes including physical exercise, weight loss, smoking cessation and stress reduction are considered effective in lowering fast HR (Fig. 1).

Despite mounting evidence linking physical inactivity to the growing and significant burden of chronic disease including CVD, this risk factor continues to be often ignored in prevention programs. Regular physical exercise results in reducing HR, increasing parasympathetic activity and decreasing sympathetic activity in the human heart at rest [71-74]. While these study protocols were different regarding the type of physical activity, duration of exercise and follow-up period, it was found that regular endurance training led to a decrease of resting $\mathrm{HR}$ and favorable modulation of autonomic neural control, which in turn may contribute to improved patient prognosis and reduced mortality. The HERITAGE Family Study found a small but statistically significant decrease of resting HR (from a minimum of 2.7 to a maximum of $4.6 \mathrm{bpm}$ ) in all healthy participants $(n=507)$ assigned to three age-related groups (17-29 years, $30-49$ years and 50-65 years) following a 20 -week endurance exercise program [72]. Aerobic physical training has been shown to improve cardiac autonomic modulation in hypertension independently of an- 
giotensin converting enzyme inhibitor treatment [75] and reduce CV mortality risk in cohort studies including hypertensive patients [76, 77]. Notably, hypertensive subjects benefit from regular physical exercise in lowering $\mathrm{BP}$ and improve $\mathrm{CV}$ outcomes [7]. While the magnitude of $\mathrm{BP}$ reduction with endurance training is greater than other types of exercise, more research is needed to determine the right dose of exercise $[78,79]$ and impact of physical activity on HR levels and associated outcomes in hypertension-induced tachycardia.

Given the link between obesity and higher resting $\mathrm{BP}$ and $\mathrm{HR}$ values and resultant autonomic impairment characterized by reduced parasympathetic activity and relative predominance of sympathetic activity [80], body weight reduction is considered as a crucial non-pharmacological approach in the treatment of tachycardia, metabolic abnormalities and elevated BP. In this context, clinically important are findings of the very recent PREVIEW lifestyle intervention study which followed-up 2,500,000 patients with obesity and pre-diabetes who underwent a low-energy diet for 8 weeks [81]. In this study men and women responded differently in terms of HR reduction $(-6.4 \pm 1.1$ in men vs. $4.9 \pm 1.1 \mathrm{bpm}$ in women). In addition to rapid weight loss, an 8-week low energy diet was associated with improvements in numerous parameters including insulin resistance, metabolic syndrome $Z$-score, C-peptide, fat mass, high density lipoprotein cholesterol, fat-free mass, hip circumference and pulse pressure [81]. Further proof for HR reduction following weight loss 2 years after gastric bypass surgery comes from the Utah Obesity Study [82]. In this study, in severely obese patients weight loss of an average of $100 \pm 37 \mathrm{lb}$ was accompanied by a reduction in resting HR by -13 bpm and improved HR recovery after exercise when compared to the non-surgical group (weight loss of $3 \pm 22 \mathrm{lb}$ and HR reduction by $-6 \mathrm{bpm})$. Whether, and to what extent lowering of HR may contribute to reduced CV mortality merits further investigation.

Further proof for reducing HR following weight loss has been demonstrated in young normotensive males who were randomized to a low-calorie diet, therapy with moxonidine, combination of both therapies and the control group [83]. Following 6 -month follow-up, weight loss of $7.6 \pm 1.9$ led to a reduction of HR by $-11.7 \pm 2.7 \mathrm{bpm}$ and MSNA by $-10.5 \pm 2.3$ bursts $/$ min which was comparable to the effects of a combination of both low-calorie diet and moxonidine. Moxonidine alone decreased HR by $-4.7 \pm 3.0$ bmp and MSNA by $-11.0 \pm 1.2$ with- out an impact on body weight [83]. These findings suggest that weight loss programs are essential in overweight subjects with the potential to reverse sympathetic CV profile prior to development of established hypertension.

Amongst lifestyle habits, hypertensive patients should be counselled to stop smoking. Both acute and chronic smoking has been directly linked to increases in BP, HR and MSNA levels [84, 85] which may play a critical mechanistic role in the development and progression of hypertension, CVD and mortality. Available evidence indicates that smoking cessation almost completely reverses risk of CVD, thereby is considered the single most effective lifestyle intervention. Quitting smoking results in a rapid and persistent drop of HR [86], improvement of HR variability [87] and exerts beneficial effects on $\mathrm{CV}$ health by reducing the increased excess risk among former smokers [88].

Stress is another major factor contributing to fast HR, development of hypertension, CVD and arrhythmias as previously reviewed in detail [89]. Non-pharmacological approaches such as transcendental meditation, yoga technique and slow breathing therapy have been shown to alter stress response, modulate cardiac autonomic regulation, increase $H R$ variability and vagal dominance [90-94].

\section{Conclusion and clinical perspectives}

Prevention of excess CV events and mortality caused by elevated HR remains a challenging problem. While elevated HR can be triggered by numerous factors, an appropriate assessment of resting HR followed by lifestyle interventions is essential in clinical practice in both patient risk stratification and prevention of tachycardia-related disease. Nearly 1 in 3 hypertensive patients commonly demonstrates hyperkinetic hypertension at the early course of the disease and tachycardia can be an indicator of established hypertension associated with obesity, metabolic abnormalities and obstructive sleep apnea. Undoubtedly, lifestyle modification is the cornerstone for the prevention of hypertension, in particular regular physical activity, weight loss and smoking cessation should be an integral part of treating resting tachycardia in uncomplicated hypertension. While studies on beta-blockers in the treatment of hypertension are inconclusive, notably a therapy with highly cardio-selective beta-blocker such as betaxolol can effectively reduce HR, BP and modulate sympathetic neural control in patients with tachycardia 
which is a strong independent risk factor for $\mathrm{CV}$ events and associated mortality. Given the lack of studies comparing head-to-head CV outcomes with the use of highly cardio selective beta-blockers (i.e. betaxolol, bisoprolol and nebivolol), there is an unmet need in continuing clinical trials in hypertension in order to determine the optimal HR levels that would preclude tachycardia-mediated organ damage.

\section{Conflict of interest: None declared}

\section{References}

1. Benjamin EJ, Virani SS, Callaway CW, et al. Heart Disease and Stroke Statistics-2018 Update: A Report From the American Heart Association. Circulation. 2018; 137(12): e67-e6e492, doi: 10.1161/CIR.0000000000000558, indexed in Pubmed: 29386200.

2. Niklas AA, Flotyńska A, Zdrojewski T, et al. Trends in hypertension prevalence, awareness, treatment, and control among Polish adults 75 years and older during 2007-2014. Cardiol J. 2018; 25(3): 333-344, doi: 10.5603/CJ.a2018.0043, indexed in Pubmed: 29671863.

3. Whelton PK, Carey RM, Aronow WS, et al. 2017 ACC/AHA/ /AAPA/ABC/ACPM/AGS/APhA/ASH/ASPC/NMA/PCNA Guideline for the Prevention, Detection, Evaluation, and Management of High Blood Pressure in Adults: Executive Summary: A Report of the American College of Cardiology/American Heart Association Task Force on Clinical Practice Guidelines. Hypertension. 2018; 71(6): 1269-1324.

4. Lewington S, Clarke R, Qizilbash N, et al. Age-specific relevance of usual blood pressure to vascular mortality: a metaanalysis of individual data for one million adults in 61 prospective studies. Lancet. 2002; 360(9349): 1903-1913, indexed in Pubmed: 12493255.

5. Julius S. The association of tachycardia with obesity and elevated blood pressure. J Pediatr. 2002; 140(6): 643-645, doi: 10.1067/ mpd.2002.125519, indexed in Pubmed: 12072864.

6. Palatini P, Rosei EA, Casiglia E, et al. Management of the hypertensive patient with elevated heart rate: Statement of the Second Consensus Conference endorsed by the European Society of Hypertension. J Hypertens. 2016; 34(5): 813-821, doi: 10.1097/ HJH.0000000000000865, indexed in Pubmed: 26982382.

7. Williams B, Mancia G, Spiering W, et al. 2018 ESC/ESH Guidelines for the management of arterial hypertension: The Task Force for the management of arterial hypertension of the European Society of Cardiology and the European Society of Hypertension: The Task Force for the management of arterial hypertension of the European Society of Cardiology and the European Society of Hypertension. J Hypertens. 2018; 36(10): 1953-2041, doi: 10.1097/HJH.0000000000001940, indexed in Pubmed: 30234752.

8. Folkow B. Physiological aspects of primary hypertension. Physiol Rev. 1982; 62(2): 347-504, doi: 10.1152/physrev.1982.62.2.347.

9. Julius S, Krause L, Schork N, et al. Hyperkinetic borderline hypertension in Tecumseh, Michigan. J Hypertens. 1991; 9(1): 77-84, doi: 10.1097/00004872-199101000-00012.
10. Esler M, Jennings G, Biviano B, et al. Mechanism of elevated plasma noradrenaline in the course of essential hypertension. J Cardiovasc Pharmacol. 1986; 8 Suppl 5: S39-S43, indexed in Pubmed: 2427882.

11. Palatini P, Casiglia E, Pauletto P, et al. Relationship of tachycardia with high blood pressure and metabolic abnormalities: a study with mixture analysis in three populations. Hypertension. 1997; 30(5): 1267-1273, indexed in Pubmed: 9369286.

12. Palatini P, Julius S. Association of tachycardia with morbidity and mortality: pathophysiological considerations. J Hum Hypertens. 1997; 11 Suppl 1: S19-S27, indexed in Pubmed: 9321736.

13. Gillman MW, Kannel WB, Belanger A, et al. Influence of heart rate on mortality among persons with hypertension: the Framingham Study. Am Heart J. 1993; 125(4): 1148-1154, indexed in Pubmed: 8465742.

14. Benetos A, Rudnichi A, Thomas F, et al. Influence of heart rate on mortality in a French population: role of age, gender, and blood pressure. Hypertension. 1999; 33(1): 44-52, indexed in Pubmed: 9931080.

15. Thomas F, Bean K, Provost JC, et al. Combined effects of heart rate and pulse pressure on cardiovascular mortality according to age. J Hypertens. 2001; 19(5): 863-869, indexed in Pubmed: 11393668.

16. Paul L, Hastie CE, Li WS, et al. Resting heart rate pattern during follow-up and mortality in hypertensive patients. Hypertension. 2010; 55(2): 567-574, doi: 10.1161/HYPERTENSIONAHA.109.144808, indexed in Pubmed: 20038750.

17. Julius S, Nesbitt S. Sympathetic overactivity in hypertension. A moving target. Am J Hypertens. 1996; 9(11): 113S-120S, indexed in Pubmed: 8931844.

18. Kannel WB, Kannel C, Paffenbarger RS, et al. Heart rate and cardiovascular mortality: the Framingham Study. Am Heart J. 1987; 113(6): 1489-1494, indexed in Pubmed: 3591616.

19. Esler M. The 2009 Carl Ludwig Lecture: Pathophysiology of the human sympathetic nervous system in cardiovascular diseases: the transition from mechanisms to medical management. J Appl Physiol (1985). 2010; 108(2): 227-237, doi: 10.1152/japplphysiol.00832.2009, indexed in Pubmed: 19940096.

20. Esler M, Lambert E, Schlaich M. Point: Chronic activation of the sympathetic nervous system is the dominant contributor to systemic hypertension. J Appl Physiol (1985). 2010; 109(6): 1996-8; discussion 2016, doi: 10.1152/japplphysiol.00182.2010, indexed in Pubmed: 20185633.

21. Greenwood JP, Stoker JB, Mary DA. Single-unit sympathetic discharge : quantitative assessment in human hypertensive disease. Circulation. 1999; 100(12): 1305-1310, indexed in Pubmed: 10491375.

22. Hering D, Kara T, Kucharska W, et al. High-normal blood pressure is associated with increased resting sympathetic activity but normal responses to stress tests. Blood Press. 2013; 22(3): 183-187, doi: 10.3109/08037051.2012.759689, indexed in Pubmed: 23356493.

23. Hering D, Kara T, Kucharska W, et al. Longitudinal tracking of muscle sympathetic nerve activity and its relationship with blood pressure in subjects with prehypertension. Blood Press. 2016; 25(3): 184-192, doi: 10.3109/08037051.2015.1121708, indexed in Pubmed: 26654200.

24. Hering D, Lambert EA, Marusic P, et al. Substantial reduction in single sympathetic nerve firing after renal denervation in patients with resistant hypertension. Hypertension. 2013; 
61(2): 457-464, doi: 10.1161/HYPERTENSIONAHA.111.00194, indexed in Pubmed: 23172929.

25. Hering D, Marusic P, Walton AS, et al. Sustained sympathetic and blood pressure reduction 1 year after renal denervation in patients with resistant hypertension. Hypertension. 2014; 64(1): 118-124, doi: 10.1161/HYPERTENSIONAHA.113.03098, indexed in Pubmed: 24732891.

26. Mancia G, Grassi G, Giannattasio C, et al. Sympathetic activation in the pathogenesis of hypertension and progression of organ damage. Hypertension. 1999; 34(4): 724-728, doi: 10.1161/01. hyp.34.4.724.

27. Schlaich MP, Kaye DM, Lambert E, et al. Relation between cardiac sympathetic activity and hypertensive left ventricular hypertrophy. Circulation. 2003; 108(5): 560-565, doi: 10.1161/01. CIR.0000081775.72651.B6, indexed in Pubmed: 12847071.

28. Grassi G, Seravalle G, Quarti-Trevano F, et al. Sympathetic and baroreflex cardiovascular control in hypertension-related left ventricular dysfunction. Hypertension. 2009; 53(2): 205-209, doi: 10.1161/HYPERTENSIONAHA.108.121467, indexed in Pubmed: 19124679.

29. Zoccali C, Mallamaci F, Parlongo S, et al. Plasma norepinephrine predicts survival and incident cardiovascular events in patients with end-stage renal disease. Circulation. 2002; 105(11): 1354-1359, indexed in Pubmed: 11901048.

30. Guzzetti S, Piccaluga E, Casati R, et al. Sympathetic predominance in essential hypertension: a study employing spectral analysis of heart rate variability. J Hypertens. 1988; 6(9): 711-717, indexed in Pubmed: 3183374.

31. Narkiewicz K, Somers VK. Interactive effect of heart rate and muscle sympathetic nerve activity on blood pressure. Circulation. 1999; 100(25): 2514-2518, indexed in Pubmed: 10604889.

32. Grassi G, Vailati S, Bertinieri G, et al. Heart rate as marker of sympathetic activity. J Hypertens. 1998; 16(11): 1635-1639, indexed in Pubmed: 9856364.

33. Salles GF, Cardoso CRL, Fonseca LL, et al. Prognostic significance of baseline heart rate and its interaction with beta-blocker use in resistant hypertension: a cohort study. Am J Hypertens. 2013; 26(2): 218-226, doi: 10.1093/ajh/hps004, indexed in Pubmed: 23382406.

34. Hering D, Kucharska W, Kara T, et al. Resting sympathetic outflow does not predict the morning blood pressure surge in hypertension. J Hypertens. 2011; 29(12): 2381-2386, doi: 10.1097/ HJH.0b013e32834c1ecd, indexed in Pubmed: 21986622.

35. Palatini P, Reboldi G, Beilin LJ, et al. Masked tachycardia. A predictor of adverse outcome in hypertension. J Hypertens. 2017; 35(3): 487-492, doi: 10.1097/HJH.0000000000001194, indexed in Pubmed: 27930441.

36. Jouven X, Empana JP, Schwartz PJ, et al. Heart-rate profile during exercise as a predictor of sudden death. N Engl J Med. 2005; 352(19): 1951-1958, doi: 10.1056/NEJMoa043012, indexed in Pubmed: 15888695.

37. Pocock SJ, Wang D, Pfeffer MA, et al. Predictors of mortality and morbidity in patients with chronic heart failure. Eur Heart J. 2006; 27(1): 65-75, doi: 10.1093/eurheartj/ehi555, indexed in Pubmed: 16219658.

38. Aune D, Sen A, ó'Hartaigh B, et al. Resting heart rate and the risk of cardiovascular disease, total cancer, and all-cause mortality: a systematic review and dose-response meta-analysis of prospective studies. Nutr Metab Cardiovasc Dis. 2017; 27(6): 504-517, doi: 10.1016/j.numecd.2017.04.004, indexed in Pubmed: 28552551.
39. Hozawa A, Ohkubo T, Kikuya M, et al. Prognostic value of home heart rate for cardiovascular mortality in the general population: the Ohasama study. Am J Hypertens. 2004; 17(11 Pt 1): 1005-1010, doi: 10.1016/j.amjhyper.2004.06.019, indexed in Pubmed: 15533725 .

40. Hozawa A, Inoue R, Ohkubo T, et al. Predictive value of ambulatory heart rate in the Japanese general population: the Ohasama study. J Hypertens. 2008; 26(8): 1571-1576, doi: 10.1097/ HJH.0b013e3283041172, indexed in Pubmed: 18622234.

41. Julius S, Palatini P, Kjeldsen SE, et al. Usefulness of heart rate to predict cardiac events in treated patients with high-risk systemic hypertension. Am J Cardiol. 2012; 109(5): 685-692, doi: 10.1016/j. amjcard.2011.10.025, indexed in Pubmed: 22169130.

42. Palatini P, Julius S. Heart rate and the cardiovascular risk. J Hypertens. 1997; 15(1): 3-17, doi: 10.1097/00004872-19971501000001.

43. Zhong $\mathrm{C}$, Zhong $\mathrm{X}, \mathrm{Xu}$ T, et al. Combined effects of hypertension and heart rate on the risk of stroke and coronary heart disease: a population-based prospective cohort study among Inner Mongolians in China. Hypertens Res. 2015; 38(12): 883-888, doi: 10.1038/hr.2015.90, indexed in Pubmed: 26289782.

44. Heidland UE, Strauer BE. Left ventricular muscle mass and elevated heart rate are associated with coronary plaque disruption. Circulation. 2001; 104(13): 1477-1482, indexed in Pubmed: 11571239.

45. Palatini P, Reboldi G, Beilin LJ, et al. Masked tachycardia. A predictor of adverse outcome in hypertension. J Hypertens. 2017; 35(3): 487-492, doi: 10.1097/HJH.0000000000001194, indexed in Pubmed: 27930441.

46. Hering D, Grassi G. Prognostic significance of masked tachycardia in hypertension: evidence from a prospective international registry. J Hypertens. 2017; 35(3): 468-470, doi: 10.1097/ HJH.0000000000001234, indexed in Pubmed: 28121837.

47. Bangalore S, Parkar S, Grossman E, et al. A meta-analysis of 94,492 patients with hypertension treated with beta blockers to determine the risk of new-onset diabetes mellitus. Am J Cardiol. 2007; 100(8): 1254-1262, doi: 10.1016/j.amjcard.2007.05.057, indexed in Pubmed: 17920367.

48. Bangalore S, Sawhney S, Messerli FH. Relation of beta-blockerinduced heart rate lowering and cardioprotection in hypertension. J Am Coll Cardiol. 2008; 52(18): 1482-1489, doi: 10.1016/j. jacc.2008.06.048, indexed in Pubmed: 19017516.

49. Ripley TL, Saseen JJ. Beta-blockers: a review of their pharmacological and physiological diversity in hypertension. Ann Pharmacother. 2014; 48(6): 723-733, doi: 10.1177/1060028013519591, indexed in Pubmed: 24687542.

50. Carlberg Bo, Samuelsson O, Lindholm LH. Atenolol in hypertension: is it a wise choice? Lancet. 2004; 364(9446): 16841689, doi: 10.1016/S0140-6736(04)17355-8, indexed in Pubmed: 15530629.

51. Larochelle $\mathrm{P}$, Tobe SW, Lacourcière Y. $\beta$-Blockers in hypertension: studies and meta-analyses over the years. Can J Cardiol. 2014; 30(5 Suppl): S16-S22, doi: 10.1016/j.cjca.2014.02.012, indexed in Pubmed: 24750978.

52. Kuyper LM, Khan NA. Atenolol vs nonatenolol $\beta$-blockers for the treatment of hypertension: a meta-analysis. Can J Cardiol. 2014; 30(5 Suppl): S47-S53, doi: 10.1016/j.cjca.2014.01.006, indexed in Pubmed: 24750981.

53. Tucker WD, Theetha Kariyanna P. Selective Beta-1-Blockers. In: StatPearls. Treasure Island, FL. 2018. 
54. Sharma AM, Pischon T, Hardt S, et al. Hypothesis: Beta-adrenergic receptor blockers and weight gain: A systematic analysis. Hypertension. 2001; 37(2): 250-254, indexed in Pubmed: 11230280.

55. Elliott WJ, Meyer PM. Incident diabetes in clinical trials of antihypertensive drugs: a network meta-analysis. Lancet. 2007; 369(9557): 201-207, doi: 10.1016/S0140-6736(07)60108-1, indexed in Pubmed: 17240286.

56. Stoschitzky K, Koshucharova G, Zweiker R, et al. Differing betablocking effects of carvedilol and metoprolol. Eur J Heart Fail. 2001; 3(3): 343-349, indexed in Pubmed: 11378006.

57. Stoschitzky K. Individual beta-blockers for individual patients. An article from the E-Journal of the ESC Council for Cardiology Practice. Vol. 6, $\mathrm{N}^{\circ} 19$. ; 15: Jan.

58. Brodde OE. Beta 1- and beta 2-adrenoceptors in the human heart: properties, function, and alterations in chronic heart failure. Pharmacol Rev. 1991; 43(2): 203-242, indexed in Pubmed: 1677200 .

59. Stoschitzky K, Sakotnik A, Lercher P, et al. Influence of beta-blockers on melatonin release. Eur J Clin Pharmacol. 1999; 55(2): 111-115, indexed in Pubmed: 10335905.

60. Stoschitzky K, Stoschitzky G, Brussee H, et al. Comparing beta-blocking effects of bisoprolol, carvedilol and nebivolol. Cardiology. 2006; 106(4): 199-206, doi: 10.1159/000093060, indexed in Pubmed: 16679760.

61. Swartz CM. Betaxolol in anxiety disorders. Ann Clin Psychiatry. 1998; 10(1): 9-14, indexed in Pubmed: 9622045.

62. Kunka RL, Wong YY, Andersen RL, et al. Steady-state fluctuation and variability of betaxolol and atenolol plasma levels. Ther Drug Monit. 1989; 11(5): 523-527, indexed in Pubmed: 2573178.

63. Jacobs MC, Lenders JW, Smits P, et al. Long-term beta 1-adrenergic blockade restores adrenomedullary activity in primary hypertension. J Cardiovasc Pharmacol. 1997; 30(3): 338-342, indexed in Pubmed: 9300318.

64. Sundlöf G, Wallin BG, Strömgren E, et al. Acute effects of metoprolol on muscle sympathetic activity in hypertensive humans. Hypertension. 1983; 5(5): 749-756, indexed in Pubmed: 6618637.

65. Cogliati C, Colombo S, Ruscone TG, et al. Acute beta-blockade increases muscle sympathetic activity and modifies its frequency distribution. Circulation. 2004; 110(18): 2786-2791, doi: 10.1161/01.CIR.0000146335.69413.F9, indexed in Pubmed: 15505096.

66. Wallin BG, Sundlöf G, Strömgren E, et al. Sympathetic outflow to muscles during treatment of hypertension with metoprolol. Hypertension. 1984; 6(4): 557-562, indexed in Pubmed: 6378790.

67. Burns J, Mary DA, Mackintosh AF, et al. Arterial pressure lowering effect of chronic atenolol therapy in hypertension and vasoconstrictor sympathetic drive. Hypertension. 2004; 44(4): 454-458, doi: 10.1161/01.HYP.0000141411.94596.0f, indexed in Pubmed: 15326085.

68. Hering D, Kucharska W, Chrostowska M, et al. Age-dependent sympathetic neural responses to $\beta$ selective beta-blockade in untreated hypertension-related tachycardia. Blood Press. 2018; 27(3): 158-165, doi: 10.1080/08037051.2018.1423543, indexed in Pubmed: 29308931.

69. Boutroy MJ, Morselli PL, Bianchetti G, et al. Betaxolol: a pilot study of its pharmacological and therapeutic properties in pregnancy. Eur J Clin Pharmacol. 1990; 38(6): 535-539, indexed in Pubmed: 1973651.

70. Huang YL, Lai CC, Wang YH, et al. Impact of selective and nonselective beta-blockers on the risk of severe exacerbations in patients with COPD. Int J Chron Obstruct Pulmon Dis. 2017; 12: 2987-2996, doi: 10.2147/COPD.S145913, indexed in Pubmed: 29066880.

71. Levy WC, Cerqueira MD, Harp GD, et al. Effect of endurance exercise training on heart rate variability at rest in healthy young and older men. Am J Cardiol. 1998; 82(10): 1236-1241, indexed in Pubmed: 9832101.

72. Wilmore J, Stanforth P, Gagnon J, et al. Heart rate and blood pressure changes with endurance training: The HERITAGE Family Study. Med Scien Sports Exercise. 2001: 107-116, doi: 10.1097/00005768-200101000-00017.

73. Carter JB, Banister EW, Blaber AP. Effect of endurance exercise on autonomic control of heart rate. Sports Med. 2003; 33(1): 33-46, doi: 10.2165/00007256-200333010-00003, indexed in Pubmed: 12477376.

74. Perini R, Tironi A, Cautero M, et al. Seasonal training and heart rate and blood pressure variabilities in young swimmers. Eur J Appl Physiol. 2006; 97(4): 395-403, doi: 10.1007/s00421-0060174-0, indexed in Pubmed: 16636862.

75. Cozza IC, Di Sacco THR, Mazon JH, et al. Physical exercise improves cardiac autonomic modulation in hypertensive patients independently of angiotensin-converting enzyme inhibitor treatment. Hypertens Res. 2012; 35(1): 82-87, doi: 10.1038/ hr.2011.162, indexed in Pubmed: 21956728.

76. Leitzmann MF, Park Y, Blair A, et al. Physical activity recommendations and decreased risk of mortality. Arch Intern Med. 2007; 167(22): 2453-2460, doi: 10.1001/archinte.167.22.2453, indexed in Pubmed: 18071167.

77. Rossi A, Dikareva A, Bacon SL, et al. The impact of physical activity on mortality in patients with high blood pressure: a systematic review. J Hypertens. 2012; 30(7): 1277-1288, doi: 10.1097/ HJH.0b013e3283544669, indexed in Pubmed: 22573122.

78. Leggio M, Bendini MG, D’Emidio S, et al. Exercise dose in clinical practice: Right is better than more. Cardiol J. 2018; 25(2): 287-288, doi: 10.5603/CJ.2018.0040, indexed in Pubmed: 29717780.

79. Kaleta AM, Lewicka E. Exercise dose in clinical practice: Should safety limits be set? Cardiol J. 2018; 25(2): 289-290, doi: 10.5603/ CJ.2018.0041, indexed in Pubmed: 29717781.

80. Rossi RC, Vanderlei LC, Gonçalves AC, et al. Impact of obesity on autonomic modulation, heart rate and blood pressure in obese young people. Auton Neurosci. 2015; 193: 138-141, doi: 10.1016/j. autneu.2015.07.424, indexed in Pubmed: 26260435.

81. Christensen P, Meinert Larsen T, Westerterp-Plantenga M, et al. Men and women respond differently to rapid weight loss: Metabolic outcomes of a multi-centre intervention study after a lowenergy diet in 2500 overweight, individuals with pre-diabetes (PREVIEW). Diabetes Obes Metab. 2018; 20(12): 2840-2851, doi: 10.1111/dom.13466, indexed in Pubmed: 30088336.

82. Wasmund SL, Owan T, Yanowitz FG, et al. Improved heart rate recovery after marked weight loss induced by gastric bypass surgery: two-year follow up in the Utah Obesity Study. Heart Rhythm. 2011; 8(1): 84-90, doi: 10.1016/j.hrthm.2010.10.023, indexed in Pubmed: 20970524.

83. Lambert EA, Sari CI, Eikelis N, et al. Effects of moxonidine and low-calorie diet: cardiometabolic benefits from combination of both therapies. Obesity (Silver Spring). 2017; 25(11): 1894-1902, doi: 10.1002/oby.21962, indexed in Pubmed: 28865109.

84. Hering D, Somers VK, Kara T, et al. Sympathetic neural responses to smoking are age dependent. J Hypertens. 2006; 24(4): 691-695, doi: 10.1097/01.hjh.0000217851.95583.57, indexed in Pubmed: 16531797. 
85. Hering D, Kucharska W, Kara T, et al. Smoking is associated with chronic sympathetic activation in hypertension. Blood Press. 2010; 19(3): 152-155, doi: 10.3109/08037051.2010.484150, indexed in Pubmed: 20429695.

86. Persico AM. Persistent decrease in heart rate after smoking cessation: a 1-year follow-up study. Psychopharmacology (Berl). 1992; 106(3): 397-400, indexed in Pubmed: 1570388.

87. Harte CB, Meston CM. Effects of smoking cessation on heart rate variability among long-term male smokers. Int J Behav Med. 2014; 21(2): 302-309, doi: 10.1007/s12529-013-9295-0, indexed in Pubmed: 23397454.

88. Mons U, Müezzinler A, Gellert C, et al. Impact of smoking and smoking cessation on cardiovascular events and mortality among older adults: meta-analysis of individual participant data from prospective cohort studies of the CHANCES consortium. BMJ. 2015; 350: h1551, doi: 10.1136/bmj.h1551, indexed in Pubmed: 25896935.

89. Hering D, Lachowska K, Schlaich M. Role of the Sympathetic Nervous System in Stress-Mediated Cardiovascular Disease. Curr Hypertens Rep. 2015; 17(10): 80, doi: 10.1007/s11906-0150594-5, indexed in Pubmed: 26318888.

90. Schneider RH, Grim CE, Rainforth MV, et al. Stress reduction in the secondary prevention of cardiovascular disease: rand- omized, controlled trial of transcendental meditation and health education in Blacks. Circ Cardiovasc Qual Outcomes. 2012; 5(6): 750-758, doi: 10.1161/CIRCOUTCOMES.112.967406, indexed in Pubmed: 23149426.

91. Tyagi A, Cohen M. Yoga and heart rate variability: A comprehensive review of the literature. Int J Yoga. 2016; 9(2): 97-113, doi: 10.4103/0973-6131.183712, indexed in Pubmed: 27512317.

92. Hering D, Kucharska W, Kara T, et al. Effects of acute and long-term slow breathing exercise on muscle sympathetic nerve activity in untreated male patients with hypertension. J Hypertens. 2013; 31(4): 739-746, doi: 10.1097/HJH.0b013e32835eb2cf, indexed in Pubmed: 23385649.

93. Lachowska K, Bellwon J, Narkiewicz K, et al. Long-term effects of device-guided slow breathing in stable heart failure patients with reduced ejection fraction. Clin Res Cardiol. 2019; 108(1): 48-60, doi: 10.1007/s00392-018-1310-7, indexed in Pubmed: 29943271.

94. Lachowska K, Bellwon J, Moryś J, et al. Slow breathing improves cardiovascular reactivity to mental stress and health-related quality of life in heart failure patients with reduced ejection fraction. Cardiol J. 2019 [Epub ahead of print], doi: 10.5603/ CJ.a2019.0002, indexed in Pubmed: 30697682. 